\title{
Microbial characteristics in homes of asthmatic and non-asthmatic adults in the ECRHS cohort
}

\section{Valkonen, M.}

2018-01

Valkonen , M , Täubel , M , Pekkanen , J , Tischer , C , Rintala , H , Zock , J -P , Casas , L , Probst-Hensch , N , Forsberg , B , Holm , M , Janson, C , Pin , I , Gislason , T , Jarvis , D , Heinrich , J \& Hyvärinen , A 2018 , ' Microbial characteristics in homes of asthmatic and non-asthmatic adults in the ECRHS cohort ' , Indoor Air , vol. 28 , no. 1, pp. 16-27 . https://doi.org/10.1111/ina.1242

http://hdl.handle.net/10138/238079

https://doi.org/10.1111/ina.12427

unspecified

publishedVersion

Downloaded from Helda, University of Helsinki institutional repository.

This is an electronic reprint of the original article.

This reprint may differ from the original in pagination and typographic detail.

Please cite the original version. 


\title{
Microbial characteristics in homes of asthmatic and non- asthmatic adults in the ECRHS cohort
}

\author{
M. Valkonen ${ }^{1,2}$ (D) | M. Täubel ${ }^{1}$ | J.Pekkanen ${ }^{1,3}$ | C. Tischer M,5,6 | H. Rintala $^{1}$ |

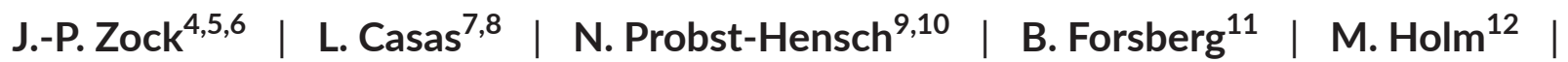 \\ C. Janson $^{13} \mid$ I. Pin ${ }^{14}$ | T. Gislason ${ }^{15,16}$ | D. Jarvis ${ }^{17,18}$ | J. Heinrich ${ }^{19,20}$ | A. Hyvärinen ${ }^{1}$ \\ ${ }^{1}$ Living Environment and Health Unit, National Institute for Health and Welfare, Kuopio, Finland \\ ${ }^{2}$ Department of Environmental and Biological Sciences, University of Eastern Finland, Kuopio, Finland \\ ${ }^{3}$ Department of Public Health, University of Helsinki, Helsinki, Finland \\ ${ }^{4}$ ISGlobal, Centre for Research in Environmental Epidemiology (CREAL), Barcelona, Spain \\ ${ }^{5}$ Universitat Pompeu Fabra (UPF), Barcelona, Spain \\ ${ }^{6}$ CIBER Epidemiología y Salud Pública (CIBERESP), Barcelona, Spain \\ ${ }^{7}$ Centre for Environment and Health - Department of Public Health and Primary Care, KU Leuven, Leuven, Belgium \\ ${ }^{8}$ Research Foundation Flanders (FWO), Brussels, Belgium \\ ${ }^{9}$ Head Department Epidemiology and Public Health, Swiss Tropical and Public Health Institute, Basel, Switzerland \\ ${ }^{10}$ Department of Public Health, University of Basel, Basel, Switzerland \\ ${ }^{11}$ Department of Public Health and Clinical Medicine, Occupational and Environmental Medicine, Umeå University, Umeå, Sweden \\ ${ }^{12}$ Department of Occupational and Environmental Medicine, Sahlgrenska University Hospital, Gothenburg, Sweden \\ ${ }^{13}$ Department of Medical Sciences, Uppsala University, Uppsala, Sweden \\ ${ }^{14} \mathrm{CHU}$ de Grenoble Alpes, INSERM U 1209, Université Grenoble Alpes, Grenoble, France \\ ${ }^{15}$ Department of Respiratory Medicine and Sleep, Landspitali University Hospital (E7), Reykjavik, Iceland \\ ${ }^{16}$ Faculty of Medicine, University of Iceland, Reykjavik, Iceland \\ ${ }^{17}$ Population Health and Occupational Disease, Imperial College, National Heart and Lung Institute, London, UK \\ ${ }^{18}$ MRC-PHE Centre for Environment and Health, Imperial College, London, UK \\ ${ }^{19}$ Institute and Outpatient Clinic for Occupational, Social and Environmental Medicine, University Hospital Munich, Ludwig Maximillians University Munich, Member \\ of German Center for Lung Research (DZL), Munich, Germany \\ ${ }^{20}$ Institute of Epidemiology I, Helmholtz Zentrum München - German Research Center for Environmental Health, Neuherberg, Germany
}

\section{Correspondence}

Maria Valkonen, Living Environment and Health Unit, National Institute for Health and Welfare, Kuopio, Finland.

Email: maria.valkonen@thl.fi

\section{Funding information}

European Commission; HITEA (Health Effects of Indoor Pollutants: Integrating microbial, toxicological and epidemiological approaches); Seventh Framework Programme, Grant/Award Number: 211488; Doctoral Programme in Environmental Health of University of Eastern Finland

\begin{abstract}
Microbial exposures in homes of asthmatic adults have been rarely investigated; specificities and implications for respiratory health are not well understood. The objectives of this study were to investigate associations of microbial levels with asthma status, asthma symptoms, bronchial hyperresponsiveness (BHR), and atopy. Mattress dust samples of 199 asthmatics and 198 control subjects from 7 European countries participating in the European Community Respiratory Health Survey II study were analyzed for fungal and bacterial cell wall components and individual taxa. We observed trends for protective associations of higher levels of mostly bacterial markers. Increased levels of muramic acid, a cell wall component predominant in Gram-positive bacteria, tended to be inversely associated with asthma (OR's for different quartiles: II
\end{abstract}


0.71 [0.39-1.30], III 0.44 [0.23-0.82], and IV 0.60 [0.31-1.18] $P$ for trend .07) and with asthma score ( $P$ for trend .06) and with atopy ( $P$ for trend .02). These associations were more pronounced in northern Europe. This study among adults across Europe supports a potential protective effect of Gram-positive bacteria in mattress dust and points out that this may be more pronounced in areas where microbial exposure levels are generally lower.

\section{KEYWORDS}

asthma, atopy, bacteria, fungi, microbial exposure

\section{1 | INTRODUCTION}

Exposure to environmental microbes may impact on human health both harmfully and beneficially. Mold and dampness at home have been associated with respiratory symptoms and asthma in adults and children ${ }^{1-4}$, and microbial exposures are believed to play a key role in these observations. A recent review has concluded on a causal relationship between indoor dampness and mold and asthma exacerbation. ${ }^{3}$ On the other hand, contacting certain microbial exposures in early life has been reported to protect from the development of asthma and allergy. ${ }^{5,6}$ Endotoxin as a part of the Gram-negative bacterial cell wall has been shown to protect from developing asthma and atopy in some studies. ${ }^{7,8}$ Richness of different fungal species in house dust $^{9-11}$ as well as certain microbial taxa has shown similar protective associations. ${ }^{9,12}$ The majority of studies on house dust microbiota and asthma and allergy target children and study the development of asthma; characteristics of house dust microbiota and asthma status in adults has been less explored.

European Community Respiratory Health Survey (ECRHS) is a large European adult population study investigating risk factors of asthma. ${ }^{13}$ In the follow-up study, ECRHS II, a subsample of the homes, was investigated for visible mold and dampness and mattress dust samples were collected from the occupants' beds. Earlier analyses within the ECRHS have found positive associations between indoor molds and dampness and health outcomes, for example, visible mold with asthma symptoms and bronchial responsiveness, ${ }^{14}$ and visible mold and water damage with new asthma cases. ${ }^{15}$ These findings are in line with a good body of literature that suggests an adverse effect of exposure to indoor dampness and mold on occupants' respiratory health via biological indoor pollution, but the causal connections and pathophysiological mechanisms are still unclear. ${ }^{4,16}$

As part of the HITEA project (Health effects of indoor pollutants: Integrating microbial, toxicological and epidemiological approaches), the aim of this study was to provide a detailed description of measurements of microbial exposures in homes of asthmatic and nonasthmatic adults. This is the most extensive asthma case-control study to-date with respect to quantitatively measuring a large repertoire of fungal and bacterial cell wall markers and more specific microbial species and groups in dust using DNA-based and chemical approaches.

\section{PRACTICAL IMPLICATIONS}

- Investigating indoor microbial exposure in homes of asthmatic and non-asthmatic adults in different European countries, we observe beneficial effects of higher bacterial, but not fungal levels in mattress dust, specifically of muramic acid, which is a cell wall component predominant in Gram-positive bacteria. Effects of exposure to microbes on asthma and atopy may be different for different geographic regions and exposure to the "right" indoor microbiota may be particularly beneficial in areas where microbial levels are overall lower.

\section{2 | MATERIALS AND METHODS}

\section{1 | Study design}

The ECRHS started as a multicenter cross-sectional study to estimate variations in the prevalence of asthma, asthma-like symptoms, airway responsiveness, and allergy and their risk factors in adults living in Europe. ${ }^{17}$ A part of the participants was followed up as and examined at ECRHS II, where 22 centers agreed to take part in a detailed assessment of home exposures, including collecting dust samples from mattress. The full protocols of this research are described at webpage http://www.ecrhs.org.

For this current study, a specific population was chosen from ECRHS II participants with frequency matching for center at 14 study centers located in different climatic regions in Europe based on a casecontrol design; 200 asthmatics and 200 center-matched controls were selected. Mattress dust samples from 199 asthmatics and 198 control subjects were analyzed for microbial content, as 3 samples had missing data. The centers, number of participants from each center, and general information of the study subjects are listed in Table 1.

\section{2 | Asthma}

The selection of subjects with current asthma was based on the following criteria at ECRHS II: positive answers to asthma ever and 
TABLE 1 Characteristics of the study population by cases and controls and numbers of study subjects per study center

\begin{tabular}{|c|c|c|}
\hline & Cases $(\mathrm{N}=198)$ & $\begin{array}{l}\text { Controls } \\
(N=199)\end{array}$ \\
\hline Parental allergy (\%) & 46.0 & 35.2 \\
\hline \multicolumn{3}{|l|}{ Smoking status (\%) } \\
\hline Lifetime non-smoker & 42.4 & 41.7 \\
\hline Ex-smoker & 35.4 & 41.2 \\
\hline Current smoker & 22.2 & 17.1 \\
\hline Atopy (\%) & 63.3 & 17.8 \\
\hline \multicolumn{3}{|l|}{ BHR slope (\%) } \\
\hline $6.01<$ & 59.2 & 13.5 \\
\hline $6.02-8.24$ & 24.2 & 40.4 \\
\hline$>8.25$ & 16.7 & 46.2 \\
\hline \multicolumn{3}{|l|}{ Household density (\%) } \\
\hline$<0.75$ people per room & 47.7 & 49.2 \\
\hline Male (\%) & 47.0 & 47.7 \\
\hline \multicolumn{3}{|l|}{ Age } \\
\hline$<38.8$ & 28.3 & 22.1 \\
\hline $38.8-45.0$ & 22.7 & 27.2 \\
\hline $45.1-49.9$ & 24.8 & 25.1 \\
\hline$>49.9$ & 24.2 & 25.6 \\
\hline \multicolumn{3}{|l|}{ No of subjects per center } \\
\hline Hamburg (Germany) & 11 & 11 \\
\hline Erfurt (Germany) & 13 & 13 \\
\hline Barcelona (Spain) & 15 & 15 \\
\hline Galdakao (Spain) & 14 & 14 \\
\hline Albacete (Spain) & 15 & 15 \\
\hline Oviedo (Spain) & 15 & 15 \\
\hline Grenoble (France) & 14 & 14 \\
\hline Ipswich (UK) & 15 & 15 \\
\hline Norwich (UK) & 14 & 15 \\
\hline Reykjavik (Iceland) & 15 & 14 \\
\hline Gothenburg (Sweden) & 15 & 15 \\
\hline Umea (Sweden) & 14 & 14 \\
\hline Uppsala (Sweden) & 13 & 14 \\
\hline Basel (Switzerland) & 15 & 15 \\
\hline Total & 198 & 199 \\
\hline
\end{tabular}

physician diagnosed asthma, as well as at least 1 positive answer to questions on asthma symptoms ("wheeze" or "chest tightness" or "attacks of breathlessness following activity or at rest" or "asthma attack" or "current medication" or "woken by attack of shortness of breath") or treatment in the past 12 months. Controls were defined as subjects, with negative answers to all above questions.

\section{3 | Asthma score}

The asthma score was used as semi-quantitative measure. The asthma score was calculated based on report of asthma symptoms in the past
12 months. ${ }^{18}$ The ordinal score, ranges from 0 to 5 , based on positive answers to questions on wheeze with breathlessness, chest tightness, attacks of shortness of breath at rest, shortness of breath after exercise, and being woken by shortness of breath.

\section{4 | Atopy}

Blood samples were taken during ECRHS II for measurement of serum immunoglobulin E (IgE). Specific lgE to house dust-mite, timothy grass, cat, and Cladosporium, as well as total IgE, were measured using the Pharmacia CAP System (Pharmacia Diagnostics, Uppsala, Sweden). Atopy was defined as at least 1 specific lgE level $>0.35 \mathrm{kU} / \mathrm{L} .{ }^{19}$

\section{5 | Bronchial hyper-responsiveness}

Bronchial hyper-responsiveness (BHR) was defined as a fall of forced expiratory volume $\left(\mathrm{FEV}_{1}\right)$ after methacholine inhalation as described previously. ${ }^{20}$ Provocation was stopped when $\mathrm{FEV}_{1}$ had dropped by $20 \%$ or after a maximum cumulative dose of $2.0 \mathrm{mg}$ of methacholine. The methacholine challenge was carried out using Mefar MB3 dosimeter (Mefar srl, Bovezzo, Italy). The dose-response "slope" (transformed log slope) was calculated and considered as an index of responsiveness, ${ }^{21}$ where a steep "slope" (low numeric value) is indicative of a high BHR.

\section{6 | Dust samples}

Mattress dust samples were collected during home visits in ECRHS II as described earlier. ${ }^{22}$ Shortly, a template of $80 \mathrm{~cm} \times 125 \mathrm{~cm}$ was placed on the area of the bed where the participant usually slept. An ALK dust collection filter (ALK-Abello, Hørsholm, Denmark) was attached to an Electrolux Mondo vacuum cleaner $(1300 \mathrm{~W})$, and the area within the template $\left(1 \mathrm{~m}^{2}\right)$ was vacuumed for 2 minutes. The dust was stored frozen at $-20^{\circ} \mathrm{C}$ until processing in 2008 at Imperial College. Dust was sieved to remove larger particles, aliquoted into subsamples, weighted, and stored at $-20^{\circ} \mathrm{C}$. A dust aliquot was shipped on dry-ice to the analyzing laboratory at the National Institute for Health and Welfare, Kuopio, Finland, in late 2008. There, the samples were weighed in 3 aliquots of 5-20 mg for the different laboratory analyses: qPCR analyses, ergosterol, muramic acid, and 3-hydroxy fatty acids (3-OHFA).

\section{7 | DNA-extraction}

DNA was extracted from the 20 mg dust samples as described ear$\operatorname{lier}^{23,24}$ using bead-beating and GenElute ${ }^{\mathrm{TM}}$ Plant genomic DNA miniprep kit (Sigma Aldrich, Saint Louis, MO, USA). Geotrichum candidum (EPA 400) was added to the samples at the beginning of the extraction and used as an internal standard.

\section{$2.8 \mid \mathrm{qPCR}$}

To quantitatively measure the concentration of certain microbial groups or species in the dust samples, 9 qPCR assays were run on the 
samples. The assays targeted fungal as well as bacterial taxa and were specific for 1 species (Alternaria alternata, A. versicolor, Cladosporium cladosporioides, Cladosporium herbarum, Cladosporium sphaerospermum), several species of 1 genus (Trichoderma viride/atroviride/koningii), 1 genus (Mycobacterium spp., Streptomyces spp.), or several genera (group of Penicillium/Aspergillus/Paecilomyces variotii; later on called as "group of Pen/Asp"). The used qPCR primers and probes have been published earlier. ${ }^{24-27}$ Detection limits for the $\mathrm{qPCR}$ varied between $<1$ and 350 cells depending on the assay. The qPCR laboratory analyses, use of internal standard, and calculations were performed as described by Kaarakainen et al, ${ }^{28}$ using the ABI Prism 7000 (Applied Biosystems, Foster City, CA, USA) and the RotorGene 3000 (Corbett Life Science, Mortlake, Australia) equipment.

\subsection{Cell wall markers of microbes}

Two aliquots of about $5 \mathrm{mg}$ of dust were used for the determination of chemical markers: 1 for ergosterol and another for 3-hydroxy fatty acids (3-OHFA) and muramic acid. The sample preparations of ergosterol and 3-OHFAs were carried out by slightly modifying the method presented by Sebastian and Larsson ${ }^{29}$ and the preparation of muramic acid by modifying the method presented by Sebastian et $a^{30}$ In our method, hexane was used instead of heptane. The ergosterol and muramic acid samples were diluted to $100 \mathrm{~mL}$ of hexane and to $150 \mathrm{~mL}$ of chloroform, respectively, before analysis by gas chromatography tandem mass spectrometry (GC-MS-MS). In the preparation of 3OHFAs, no water was used in the first extraction. The analyses of ergosterol and muramic acid were performed with a PolarisQ ion trap mass spectrometer (MS-MS) from Thermo (Austin, TX, USA) equipped with a Trace GC-ultra gas chromatograph (GC) from (Milan, Italy) with a DB-5MS fused silica capillary column from J\&W Scientific (Folsom, CA, USA). Detection limits for the chemical markers were between 1.0 and $5.4 \mathrm{ng} /$ sample. Lipopolysaccharide (LPS) amount was calculated as the sum of 10-16 chain length 3-OHFA's divided by 4, based on the knowledge that 4 mol of 3-OHFA's corresponded to 1 mole of LPS, as described earlier. ${ }^{31}$

\subsection{0 | Statistical analyses}

Statistical analyses were performed using SAS (version 9.2, SAS Institute Inc., Cary, NC, USA) and with the SPSS statistical (22.0.).

Microbial data were categorized into either quartiles or tertiles if there were many values below detection limit: first tertile below detection limit, second below the median of detectable values, and third above the median of detectable values. Additionally, microbial data were presented as interquartile range (IQR) for the analyses with health outcomes. Zero was used for non-detects for all data.

A "total microbial content" variable was built as follows: each single microbial cell wall marker (MuAc, LPS, and ergosterol) was first divided into 5 groups using quintiles as cutoffs. Quintiles got values 0, 1, 2, 3 , and 4 from lowest to highest. Finally, values from all markers were summed to get a score ranging from 0 to 12 . These score values were used in statistical analyses as a variable "Sum (MuAC, LPS, Ergosterol)."
For the geographic variation analyses, study subjects were classified into 3 climatic areas: North Europe ( $N=115$, including subjects from Reykjavik, Göteborg, Umea, Uppsala centres), central Europe ( $N=166$, including subjects from Hamburg, Erfurt, Grenoble, Ipswich, Norwich, Basel centres), and South Europe ( $N=119$, including subjects from Barcelona, Galdakao, Albacete, Oviedo centres).

Weighted logistic regression analyses and weighted regression analyses were used to investigate associations between the categorized microbial parameters and health outcomes. Analyses for all health outcomes other than asthma were weighted. Weights were calculated based on the asthma case status and center. Trend test analysis was used to investigate monotonic order of the categorized microbial groups and their associations with health outcomes. The association between the health outcomes and the log-transformed concentrations of microbial markers was assessed using mixed negative binomial regression analysis. To allow for log-transformation of datasets with zero values, we used In(value+1). All models were adjusted for parental allergy, smoking status, household density, gender, age, and center. Confounders were selected a priori based on previous studies. Correlations between microbial parameters were analyzed using Spearman's rho correlation coefficients. Interactions of microbial markers with geographic area for analyses on asthma were also tested.

\section{3 | RESULTS}

We observed fairly large variations of the different microbial exposures in study centers across Europe (up to 25-fold differences between medians for qPCR markers and up to 4-fold differences for cell wall markers between centers; Table S1). There was no clear common geographic trend for North, Central, and South Europe that would apply consistently for all microbial parameters (Figure 1). Prevalence and levels of the individual microbial parameters are presented in Table 2. Determinations of cell wall components of bacteria (muramic acid, LPS) and fungi (ergosterol) as well as most of the GPCR assays of microbial genera or groups returned values above detection limits for all or most of the samples, while some of the species-specific qPCR assays (Alternaria alternata, A. versicolor, Trichoderma viride/atroviride/koningii) led to high numbers of results below detection limit (65\%-88\%; Table 2 ).

Correlations between the microbial parameters are presented in Table 3. Correlations were mostly low, with Spearman correlation coefficients rarely exceeding 0.3 . Good correlations were observed between the Cladosporium species $C$. herbarum and C. cladosporioides. Significant correlations were observed within a cluster constituted by C. herbarum, C. cladosporioides, A. alternata, and the bacterial genera Mycobacterium spp., and Streptomyces spp., with correlation coefficients ranging from 0.32 to 0.72 .

\section{1 | Microbial parameters and asthma, asthma score, and BHR}

Considering general cell wall markers of microbial exposure in the whole study population, we observed inverse (protective) associations 

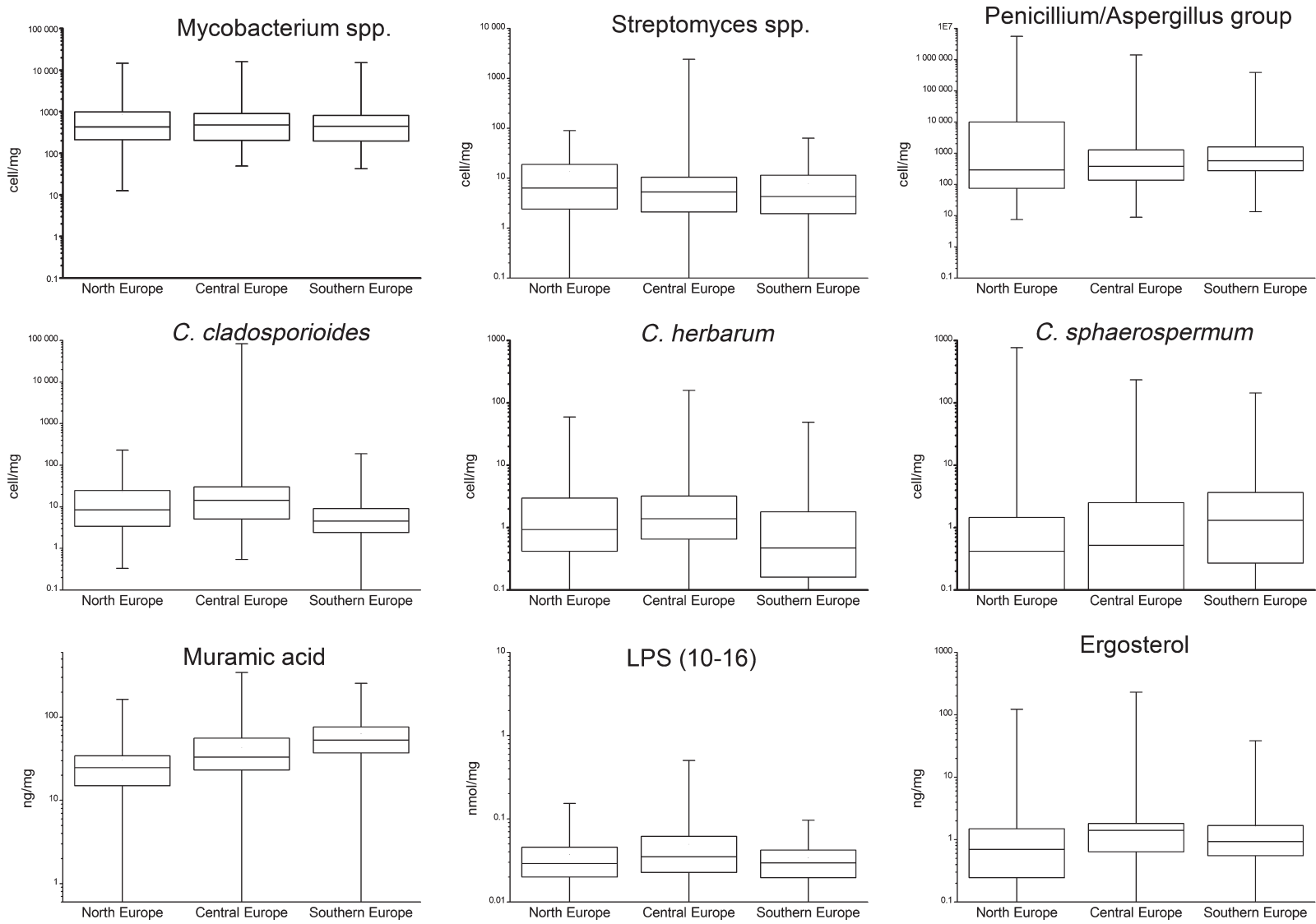

FIGURE 1 Levels of log-transformed microbial markers in dust samples of the ECRHS II with study centers categorized into 3 geographic areas (Box plots show min, 25th percentile, median, 75th percentile, max). Markers with prevalence $>50 \%$ are shown

\begin{tabular}{|c|c|c|c|c|c|}
\hline Microbe/marker & $\mathrm{N}$ & 25th percentile & Median & 75th percentile & LOD (\%) \\
\hline \multicolumn{6}{|l|}{ qPCR } \\
\hline Alternaria alternata & 397 & 0 & 0 & 16.5 & $284(71.5)$ \\
\hline Aspergillus versicolor & 397 & 0 & 0 & 0 & $351(88.4)$ \\
\hline $\begin{array}{l}\text { Cladosporium } \\
\text { cladosporioides }\end{array}$ & 397 & 3.3 & 7.7 & 22 & $1(0.25)$ \\
\hline Cladosporium herbarum & 397 & 0.4 & 1 & 2.7 & $4(1.0)$ \\
\hline $\begin{array}{l}\text { Cladosporium } \\
\text { sphaerospermum }\end{array}$ & 397 & 0.0 & 0.7 & 2.2 & $125(31.5)$ \\
\hline Group of Pen/Asp & 397 & 140.5 & 458.5 & 1784.5 & $0(0)$ \\
\hline $\begin{array}{l}\text { Trichoderma viride } \\
\text { group }\end{array}$ & 397 & 0 & 0 & 0.1 & $256(64.5)$ \\
\hline Mycobacterium spp. & 394 & 204.4 & 454.9 & 945.6 & $0(0)$ \\
\hline Streptomyces spp. & 397 & 2.1 & 5.2 & 12.7 & $8(2.0)$ \\
\hline \multicolumn{6}{|l|}{ Cell wall markers } \\
\hline Muramic acid (ng/mg) & 394 & 22.8 & 34.5 & 58.2 & $16(4.1 \%)$ \\
\hline LPS (nmol/mg) & 391 & 0.02 & 0.03 & 0.05 & $30(7.7 \%)$ \\
\hline Ergosterol (ng/mg) & 397 & 0.49 & 1.11 & 1.72 & $56(14.1 \%)$ \\
\hline
\end{tabular}

TABLE 2 Descriptive statistics of microbial groups measured by qPCR (cells/ mg dust) and of cell wall markers

LOD, lower limit of detection.

of the bacterial muramic acid and total microbial content (sum of muramic acid, LPS, and ergosterol) in mattress dust with asthma (Table 4). Inverse associations were borderline significant for muramic acid (middle group; trend test $P$-value .07), and this was consistent with findings for the asthma score (borderline significant, $P=.06$; Table 5), but not with BHR (Table 4). Adding other cell wall markers (LPS and 
TABLE 3 Correlations between microbial markers

\begin{tabular}{|c|c|c|c|c|c|c|c|c|c|c|c|c|}
\hline & Aaltr & Avers & Cclad & Cherb & Cspha & PenAsp & Tviri & Myco & Strep & MuAc & LPS & Ergo \\
\hline Aspergillus versicolor & 0.06 & 1 & & & & & & & & & & \\
\hline Cladosporium herbarum & $0.42^{c}$ & -0.01 & $0.72^{\mathrm{C}}$ & 1 & & & & & & & & \\
\hline Pen/Asp group & $0.20^{c}$ & $0.32^{c}$ & $0.22^{c}$ & $0.20^{c}$ & $0.31^{c}$ & 1 & & & & & & \\
\hline Trichoderma viride group & $0.22^{c}$ & $0.16^{\mathrm{b}}$ & $0.24^{c}$ & $0.17^{c}$ & $0.23^{c}$ & $0.23^{c}$ & 1 & & & & & \\
\hline Mycobacterium spp. & $0.15^{\mathrm{b}}$ & 0.07 & $0.37^{c}$ & $0.32^{c}$ & 0.19 & $0.12^{\mathrm{a}}$ & $0.24^{c}$ & 1 & & & & \\
\hline Streptomyces spp. & $0.33^{c}$ & $0.10^{\mathrm{a}}$ & $0.58^{\mathrm{c}}$ & $0.48^{c}$ & $0.22^{c}$ & $0.33^{c}$ & $0.34^{c}$ & $0.40^{c}$ & 1 & & & \\
\hline
\end{tabular}

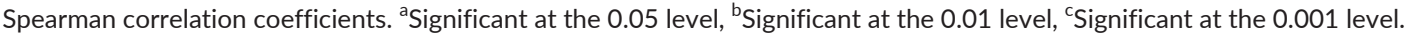

ergosterol) to the regression model did not change the association of muramic acid with asthma (data not shown). Gram-negative bacterial LPS showed a non-significant inverse association with asthma status ( $P$ for trend test .10), but not with asthma symptom score (Table 5), and a borderline significant inverse association on BHR (trend test $P=.06$; Table 4). In an exploratory, post hoc analysis, we also created a score based on LPS and muramic acid, a "total bacterial content" variable. We observed significant inverse associations in the highest quartiles with asthma (OR [95\% Cl] for second to forth quartiles: II 1.15 [0.64-2.05], III 0.50 [0.25-1.01], IV 0.51 [0.27-0.99]; $P$ for trend test <.01) and for atopy II (1.49 [0.53-4.14], III 1.13 [0.37-3.45], IV 0.26 [0.08-0.87]; P for trend test .04). Associations with BHR slope were significant in the third quartile (0.89 [0.05-1.72]; $P$ for trend test .07). Higher "total microbial content" showed an inverse dose-response trend with asthma, asthma score, and BHR slope, but findings did not reach statistical significance. Analyses of these associations by geographic region revealed that the inverse association of muramic acid on asthma status was statistically significant only in northern Europe (Figure 2, Tables S2-S4).

Measurements of more specific fungal and bacterial taxa using qPCR were negatively associated with asthma status for Cladosporium species and Streptomyces spp. in the whole population, whereas A. versicolor and group of Penicillium/Aspergillus/Paecilomyces variotii tended to positively associated with asthma (Table 4). Elevated levels of the bacterial genus Mycobacterium were significantly inversely associated with asthma status (middle group; $P$ for trend test .12), but showed a significant positive association with BHR slope and a trend for higher asthma symptom score (Tables 4 and 5). Overall, no statistically significant associations were found between the asthma score and microbial genera, species, or groups determined with qPCR (Table 5). Analyses by region showed inverse trend for Mycobacterium spp. in southern Europe (Figure 2), and an inverse association with BHR slope in southern and northern Europe (Figure S1). Streptomyces spp. was inversely associated with asthma status in northern Europe (Figure 2). Analyses of microbial markers versus asthma were also performed adjusted for pet keeping and dampness in homes, but those adjustments did not change our observations (data not shown).

Only 1 interaction between microbial marker and area, muramic acid, reached a $P$-value below $0.2(P=.11$ unadjusted; $P=.17$ adjusted for parental allergy, smoking status, household density, sex, age, center, and area; data not shown).

\subsection{Microbial parameters and atopy}

For atopy, both protective and risk associations with microbial parameters were observed. Significant protective associations in the whole population were mostly seen for the general bacterial cell wall markers muramic acid (trend test $P=.02$ ) and LPS (highest category) and $C$. cladosporioides (trend test $P=.04$ ). Risk associations were observed with some fungal exposures and findings were significant for Trichoderma viride (trend test $P=.03$ ). The risk associations of fungal parameters were most pronounced in northern Europe (significant risk for ergosterol and T. viride), and the protective qualities of bacterial cell wall agents and total microbial exposure on atopy were more pronounced in northern and southern Europe (Figure 2).

\section{4 | DISCUSSION}

In this case-control study on prevalent asthma within the adult population of ECRHS II, we found inverse associations of higher levels of mainly the bacterial markers in North Europe with asthma status, asthma symptom score, and measured BHR, as well as with atopy. Overall, significant observations were little consistent between different regions in Europe and between the different outcomes assessed, but the findings were most consistent for muramic acid, and a similar 
TABLE 4 Adjusted associations of mattress dust concentrations of microbial markers on asthma, atopy, and weighted bronchial hyperresponsiveness (BHR) slope (negative regression coefficient in BHR slope indicates risk association with the exposure)

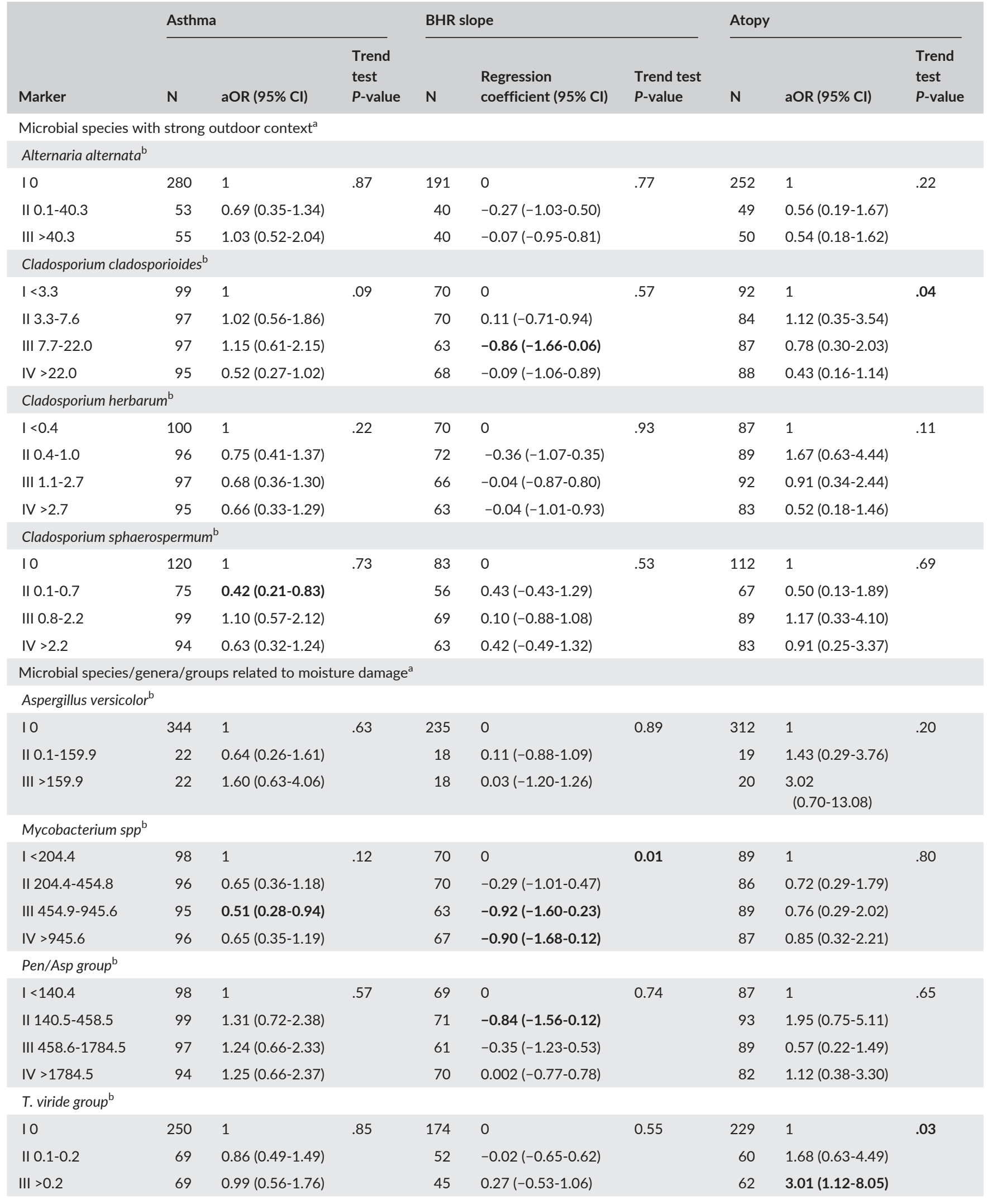


TABLE 4 (Continued)

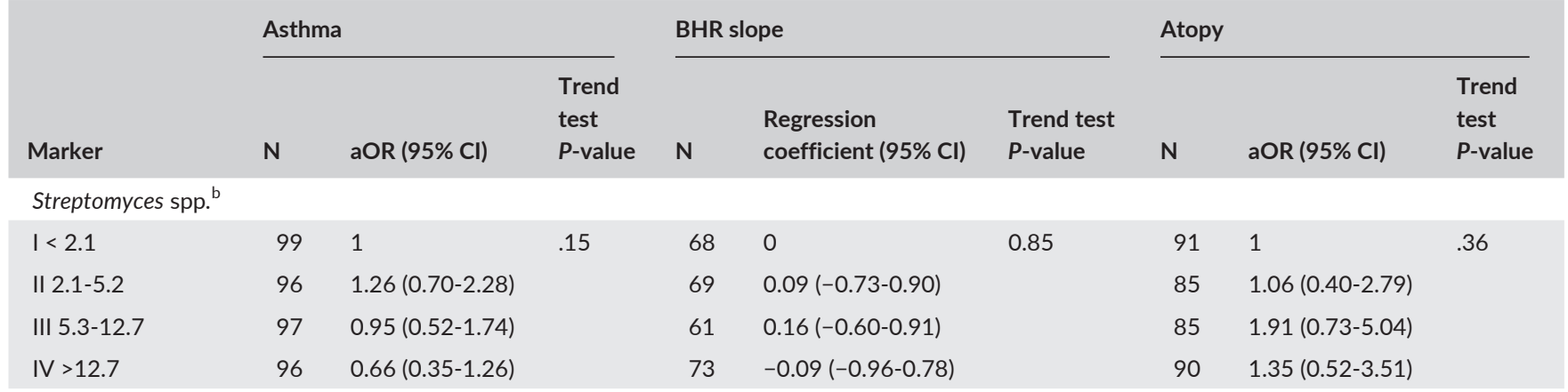

Markers of bacterial, fungal, and total microbial content

Muramic acid

\begin{tabular}{|c|c|c|c|c|c|c|c|c|c|}
\hline $1<2.3$ & 96 & 1 & .07 & 69 & 0 & 0.51 & 89 & 1 & .02 \\
\hline II 2.3-3.4 & 98 & $0.71(0.39-1.30)$ & & 64 & $-0.27(-0.98-0.45)$ & & 92 & $1.73(0.66-4.54)$ & \\
\hline III 3.5-5.8 & 95 & $0.44(0.23-0.82)$ & & 69 & $-0.45(-1.26-0.36)$ & & 81 & $0.51(0.18-1.45)$ & \\
\hline IV $>5.8$ & 96 & $0.60(0.31-1.18)$ & & 67 & $0.41(-0.34-1.16)$ & & 86 & $0.38(0.12-1.17)$ & \\
\hline \multicolumn{10}{|l|}{$\operatorname{LPS}(10-16)^{d}$} \\
\hline $\mid<0.02$ & 99 & 1 & .10 & 69 & 0 & 0.06 & 88 & 1 & .12 \\
\hline II 0.02-0.03 & 92 & $0.77(0.43-1.38)$ & & 67 & $0.35(-0.43-1.14)$ & & 83 & $0.79(0.29-2.13)$ & \\
\hline III 0.04-0.05 & 95 & $0.58(0.32-1.05)$ & & 56 & $0.55(-0.35-1.44)$ & & 83 & $1.04(0.37-2.95)$ & \\
\hline IV $>0.05$ & 96 & $0.64(0.35-1.20)$ & & 74 & $0.83(-0.06-1.72)$ & & 91 & $0.33(0.10-1.04)$ & \\
\hline \multicolumn{10}{|l|}{ Ergosterol $^{\mathrm{e}}$} \\
\hline $\mid<493$ & 98 & 1 & .42 & 71 & 0 & 0.53 & 89 & 1 & .58 \\
\hline || 493-1113 & 98 & $1.58(0.85-2.94)$ & & 64 & $-0.66(-1.50-0.18)$ & & 87 & $1.25(0.45-3.48)$ & \\
\hline III 1114-1715 & 96 & $1.20(0.64-2.26)$ & & 62 & $0.07(-0.85-0.99)$ & & 86 & $1.16(0.38-3.52)$ & \\
\hline IV >1715 & 96 & $1.37(0.72-2.63)$ & & 74 & $0.28(-0.63-1.20)$ & & 89 & $1.39(0.45-4.27)$ & \\
\hline \multicolumn{10}{|c|}{ Total microbial content } \\
\hline $1<3$ & 65 & 1 & .10 & 45 & 0 & 0.19 & 61 & 1 & .17 \\
\hline II 4-5 & 110 & $1.04(0.54-2.00)$ & & 69 & $-0.14(-1.02-0.74)$ & & 98 & $1.55(0.52-4.60)$ & \\
\hline III 6 & 43 & $0.93(0.41-2.12)$ & & 31 & $-0.16(-1.48-1.16)$ & & 39 & $1.21(0.27-5.49)$ & \\
\hline IV 7-8 & 102 & $0.67(0.34-1.32)$ & & 74 & $0.29(-0.59-1.18)$ & & 88 & $0.76(0.24-2.40)$ & \\
\hline$V>8$ & 62 & $0.56(0.26-1.23)$ & & 47 & $0.63(-0.37-1.63)$ & & 59 & $0.34(0.09-1.25)$ & \\
\hline
\end{tabular}

Adjusted for parental allergy, smoking status, household density, gender, age, and center. Analyses for atopy and BHR slope were weighted. Markers were classified into 4 classes: I = 0-25 percentile, II = 25-50, III = 50-75, IV = 75-100 or into 3 classes, if there were many below detection limit values: I = 0 (below detection limit), II = below median, III = above median. For Cladosporium sphaerospermum, the first class is below detection limit. Associations with $P<.05$ are in bold.

${ }^{\mathrm{a}}$ Based on literature reports.

${ }^{\mathrm{b}} \mathrm{Cells} / \mathrm{mg}$.

cng/mg.

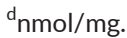

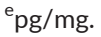

trend was noticeable for lipopolysaccharide of Gram-negative bacteria in central and southern Europe. We observe that Gram-positive bacteria showed protective associations predominantly in northern countries, where microbial exposures were generally lower. Most of the fungal parameters were not statistically significantly associated with health outcomes, although some trends with risk of asthma were seen with A.versicolor and group of Penicillium/Aspergillus/ Paecilomyces variotii.

Muramic acid is a major structural component of the peptidoglycan layer in the cell wall of Gram-positive bacteria and is thus considered a marker of predominantly Gram-positive bacteria, although it does occur also to a smaller extent in cell walls of Gram-negative bacteria. Studies have shown that peptidoglycan activates the innate immune response via Toll-like receptor 2 (TLR-2) and has immunomodulatory qualities. ${ }^{32-36}$ Some previous studies in children have mainly reported protective associations of higher muramic acid levels with wheezing and asthma. Muramic acid in mattress dust has been associated with lower prevalence of wheezing and asthma in a population of farming and non-farming school-aged children in Europe independently of farming status or endotoxin levels in the dust samples. ${ }^{37}$ This same 
TAB LE 5 Associations of log-transformed microbial concentrations with asthma score tested using negative binomial regression analysis. Ratios were exponentially back transformed

\begin{tabular}{|llll|}
\hline & $\begin{array}{l}\text { Asthma score } \\
\text { mean ratio }\end{array}$ & $95 \% \mathrm{Cl}$ & P-value \\
\hline $\begin{array}{l}\text { Alternaria alternata } \\
\begin{array}{l}\text { Cladosporium } \\
\text { cladosporiodes }\end{array}\end{array}$ & 0.98 & $(0.82-1.18)$ & .85 \\
\hline Cladosporium herbarumz & 1.00 & $(0.85-1.17)$ & .97 \\
\hline $\begin{array}{l}\text { Cladosporium } \\
\text { sphaerospermum }\end{array}$ & 0.95 & $(0.83-1.09)$ & .49 \\
\hline Mycobacteria spp. & 1.10 & $(0.84-1.08)$ & .48 \\
\hline Group of Pen/Asp & 0.92 & $(0.96-1.26)$ & .17 \\
\hline Streptomyces spp. & 1.03 & $(0.82-1.04)$ & .20 \\
\hline T. viride group & 0.98 & $(0.87-1.22)$ & .76 \\
\hline Ergosterol & 0.95 & $(0.95-1.02)$ & .38 \\
\hline Muramic acid & 0.88 & $(0.86-1.05)$ & .30 \\
\hline LPS 10-16 & 1.02 & $(0.78-1.01)$ & .06 \\
\hline Total microbial content & 0.88 & $(0.89-1.17)$ & .73 \\
\hline
\end{tabular}

Estimates calculated for an interquartile change. Adjusted for case, parental allergy, smoking status, household density, gender, age, and center.

\section{Asthma}

SOUTH EUROPE SUM (Ergo Muac LPS) $\mathrm{MuAc}$
Ergosterol Ergosterol Streptomyces Pen/Asp group Mycobacteria C. sphaerospermum C. herbarum

C. cladosporioides A. alternata

CENTRAL EUROPE SUM (Ergo Muac LPS) LPS Ergosterol T. viride Streptomyces Pen/Asp group Mycobacteria C. sphaerospermum C. herbarum C. cladosporioides A. alternata

NORTH EUROPE SUM (Ergo Muac LPS)

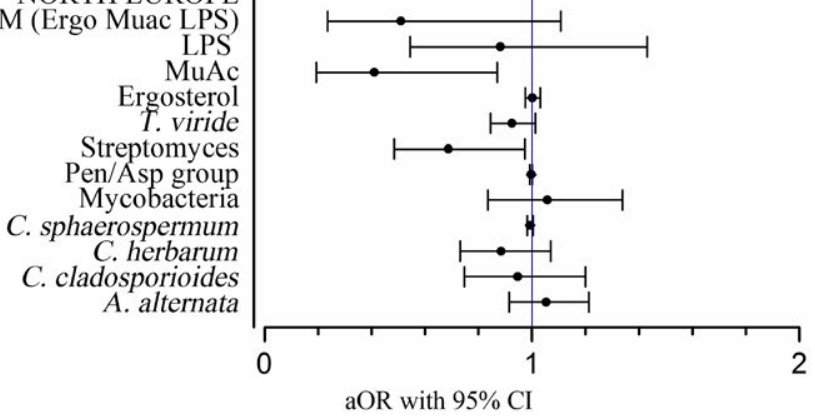

study did not find associations of muramic acid with atopy. Similarly, muramic acid levels in bed dust, but not floor dust collected in children's homes (at age 7) in the Boston metropolitan area, were inversely associated with current asthma, but not with allergic sensitization. ${ }^{8}$ Weber et $\mathrm{al}^{38}$ reported inverse associations of muramic acid load in floor, but not mattress dust with asthma in school-aged children in a cross-sectional analysis of a German birth cohort.

To our knowledge, there is only 1 comparable study which investigated the associations between microbial exposures measured in the home environment with respiratory disorders in adults. A recent study that had its population also drawn from the ECRHS II cohort reported an association of higher levels of muramic acid in mattress dust with the asthma symptom score, ${ }^{39}$ an effect opposite to the current findings. Tischer et al utilized a population of 956 subjects in 22 centers from 10 countries, whereas our current study analyzed 397 study subjects from 14 centers located in 7 countries in an asthma case-control design; the 2 study populations did not overlap as concerns the study participants. The differences between the 2 studies with respect to the participating centers concerned mostly central and southern Europe. Approximately $5 \%$ of the study population used in the earlier analyses had an asthma symptom score of 3 or more and $64 \%$ had a score of
Atopy

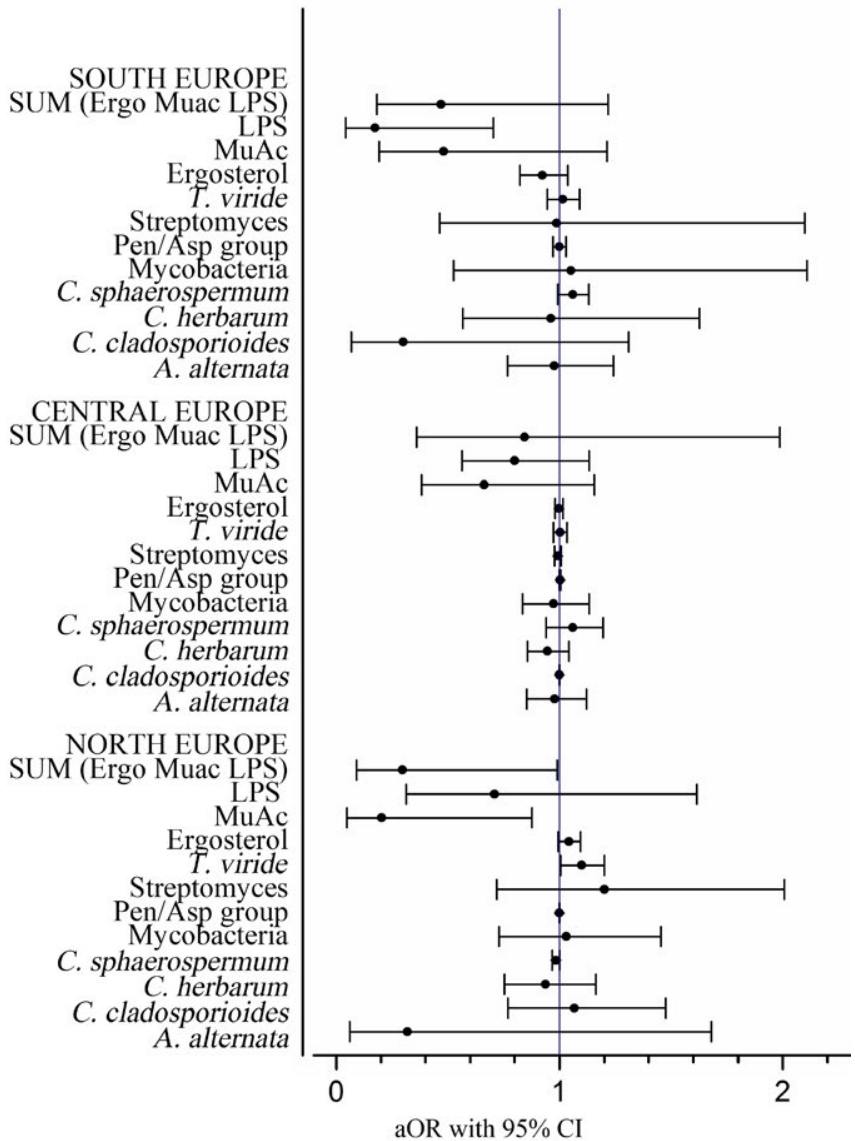

FIGURE 2 Associations of microbial markers with asthma and atopy by geographic region (South, Central, North Europe). Adjusted for parental allergy, smoking status, household density, gender, age, and center. aOR's estimated for 1 interquartile change in the microbial marker. For atopy, analyses are weighted 
zero, whereas in our current study, it was $21 \%$ of the study subjects with a score of equal or higher 3 and $50 \%$ (the controls) with a score of zero. In the earlier study, condensation on the bedroom windows and wet or damp spots in the home were frequently observed ( $>20 \%$ ), and water damage and damp patches increased muramic acid concentrations. In our current study, prevalence of wet or damp spots in the last 12 months was $21 \%$, but we did not observe correlations between dampness indicators and muramic acid levels (data not shown). These marked differences in the 2 study populations may well explain the diverging findings of the associations between muramic acid and the asthma symptom score, in particular given that we observe a dependency of the association by geographic region, with effects being pronounced in the northern European countries. Differences in factors that were adjusted for in respective statistical analyses may have also added to this observation.

A major source of bacteria indoors is known to be human related and this is particularly true when considering mattress dust as a sample material for analyses of indoor microbiota. ${ }^{40}$ Human skin is rich of Gram-positive bacteria of the Actinobacteria and Firmicutes phyla, and skin and other material of human origin are likely to be the major source of the Gram-positive bacteria and thus muramic acid in our study as well. However, significantly elevated concentrations of muramic acid have been found from farm children's mattress dust compared to non-farmers, ${ }^{37}$ which indicates that environmental sources are well reflected also in mattress dust. Sordillo et $\mathrm{al}^{41}$ found that frequent bedroom cleaning and season of sampling had significant impacts on muramic acid levels in a cohort of Boston metropolitan area homes. Tischer et $\mathrm{al}^{39}$ found water damage, pets allowed in the bedroom, current smoking, season, and latitude to be significantly associated with the mattress dust muramic acid content. ${ }^{39}$ It is evident that mattress dust does reflect not only human-derived but also environmental sources and that the associations found in our study may relate to differences in environmental microbial exposure in the study homes.

A study carried out in homes of Finnish and Russian Karelia, 2 areas in very close geographic vicinity with high similarity in vegetative and climatic conditions found a striking overrepresentation of Grampositive bacterial content in dust collected in Russian Karelian homes. ${ }^{42}$ Main differences based on DNA sequencing were attributable to bacterial sequences of the Staphylococcaceae and Corynebacteriaceae. The authors suggested a dominance of animal-associated bacterial species in dust from Russian Karelia due to a more emphasized contact between humans and animals (livestock and pets), opposed by more vegetation-associated species found in the Finnish homes, and also linking to difference in prevalence of allergic symptoms and diseases. ${ }^{43}$ In our current study, we need to rely on interpreting findings based on muramic acid as a general marker for Gram-positive bacteria without further resolution and ability to reflect animal, human, or vegetation as sources. We can only hypothesize that similar lifestyle factors relating to closer animal contact may explain the findings in our study.

Avoidance behavior due to respiratory health problems or allergy, that is, increased cleanliness and hygiene measures being implemented in homes of asthmatics could provide another explanation for our observations. Cleaning habits have been shown to affect the muramic acid content in mattress dust in a study in the US. ${ }^{41} \mathrm{~A}$ German study, however, found no association between a home cleanliness score and a personal cleanliness score with load or concentration of muramic acid in mattress and floor dust samples, while amounts of dust were indeed reduced by increased cleanliness measures. ${ }^{38}$

It is well known that exposure to microbes provides immune stimulus or challenge, which probably protects from developing asthma or allergic diseases. ${ }^{5}$ This could explain the protective effects of bacterial agents in mattress dust we see in our study. The protective quality of microbial exposure is generally believed to be relevant in early childhood, whereas we were investigating an adult population in this study. One could speculate that avoidance of animal contact by our asthmatic subjects would explain in the lower home dust Gram-positive bacterial levels. This was not, however, the case; a similar effect of low animal contact also on levels of Gram-negative bacterial LPS would be expected, which at least in the analysis by geographic region was not observed. Also, the fact that adding other general microbial markers (LPS and ergosterol) in the same model with muramic acid did not change the protective associations with asthma status indicates that general cleanliness measures may not be the driving factor underlying the lower muramic acid levels in the homes of the asthmatics. Assumption on lifetime exposure to indoor microbes is difficult or impossible to make based on a cross-sectional study as the current, with exposure and health assessment being performed later in life. In summary, the factors underlying and mechanisms explaining the observed inverse relation between Gram-positive bacterial levels in mattress dust and asthma and atopy cannot be explained based on our current analyses. These are issues that will remain to be answered in future, longitudinal studies.

The prevalence and levels of the detected microbial parameters varied largely between different study centers and areas across Europe. Tischer et $\mathrm{al}^{39}$ have observed that latitude has a significant effect on a number of microbial parameters: increasing latitude increased C.herbarum levels and decreased group of Penicillium/ Aspergillus/Paecilomyces variotii and muramic acid levels. Large geographic variation of microbial markers has been reported earlier in a larger sample of the ECRHS II with endotoxin. ${ }^{44}$ In our study, the concentration of muramic acid in mattress dust was found to be lowest in northern Europe, where at the same time the protective effect of elevated levels on both respiratory health and atopy was strongest. An earlier ECRHS study detected very low exposures to allergens, molds, and bacteria especially in Reykjavik, where also the allergic sensitizing was lowest. ${ }^{45}$ The observations of a protective association of elevated microbial levels, especially in an area of generally lower exposure, are certainly intriguing and should motivate future research efforts.

Exposure to fungal markers increased, mostly non-significantly, the risk of respiratory outcomes and atopy in our study, with the exception of Cladosporium species. The latter, mostly outdoor air-related species, showed a trend toward protective associations at higher levels. Correlations between microbial parameters were generally poor to moderate, but revealed 2 distinct clusters including microbial parameters that may represent similar sources. The first group of markers included A. alternata, C. cladosporioides, C. herbarum, Streptomyces spp., Mycobacterium spp., and LPS. These parameters probably are 
strongly determined by outdoor sources and members of this group were mostly inversely associated with respiratory health and atopy, indicating that exposure to microbes from outdoor sources could represent a rather protective scenario. It is also possible that the increased presence of outdoor-derived microbes indicates more efficient replacement of indoor pollutants with potential health implications by outdoor air. The second group centering around Penicillium/Aspergillus/ Paecilomyces variotii included significant correlations between 0.22 and 0.32 with $A$. versicolor, C. sphaerospermum, and ergosterol that may be linked mainly to building or indoor sources. The fungal species A. versicolor and Trichoderma viride and the fungal group of Penicillium/ Aspergillus/Paecilomyces variotii showed mostly non-significant trends to risk association with asthma and/or atopy. These fungal groups are generally known to be associated with indoor dampness, ${ }^{46}$ and exposure to these species has been associated previously with asthma. ${ }^{47,48}$ A multitude of studies has shown associations of observed indoor dampness and visible mold with respiratory symptoms. ${ }^{1,3,4,49}$ Also in earlier studies of the ECRHS, visible mold or damp patches assessed with questionnaire have been associated with increased prevalence of asthma symptoms, diagnosed asthma, lung function, and BHR. ${ }^{15,50}$ A discrepancy between relationships of observed versus measured molds with respiratory health has been repeatedly acknowledged. ${ }^{4,51}$

In this current study, levels of microbial concentrations were generally low, especially those analyzed with qPCR. The DNA extraction method used in this case-control study involved powerful cleaning steps to overcome issues with PCR inhibitors, which explains the generally low levels reported based on the qPCR analyses. The DNA extraction procedures have been upgraded and changed in the analyzing laboratory, which is confirmed by the generally higher levels of some of the same qPCR markers in a recently reported study within the ECRHS II cohort. ${ }^{39}$ However, our analyses included the use of internal standard, both in the DNA-based qPCRs as well as in the chemical analytical analyses of cell wall agents, taking into account inhibition and analyte losses during the laboratory process. Thus, while the absolute, microbial levels determined in this study might not be well comparable to other, more recent studies that used improved DNA extraction approaches, the results are robust within the current study and comparable between subjects. Especially fungal material was present in rather small amounts in mattress dust, which is supported by the finding that ergosterol, which is a general fungal marker and integral part of the fungal cell wall, was below detection limit in $12 \%$ of the samples.

In conclusion, this is a large cross-sectional asthma case-control study among adults across Europe that highlights the potential protective associations of bacteria and in particular of Gram-positive bacteria in mattress dust with asthma and atopy. Our findings indicate that a protective effect of higher microbial exposure in an adult population may be modified by geographic region and may occur especially in regions where general microbial levels are lower.

\section{ACKNOWLEDGEMENT}

This work was supported by the European Commission as part of HITEA (Health Effects of Indoor Pollutants: Integrating microbial, toxicological and epidemiological approaches), Grant agreement no. 211488 under the Seventh Framework Programme. Work of Maria Valkonen was supported by the Doctoral Programme in Environmental Health of University of Eastern Finland. Lidia Casas is the recipient of a post-doctoral fellowship of the Fonds Wetenschapelijk Onderzoek Vlaanderen - Research Foundation Flanders (FWO), grant number $12 I 1517 \mathrm{~N}$.

\section{ORCID}

M. Valkonen (iD http://orcid.org/0000-0002-4723-5654

\section{REFERENCES}

1. Institute of Medicine. Damp Indoor Spaces and Health. Washington, DC: The National Academies Press; 2004

2. World Health Organization. WHO Guidelines for Indoor Air Quality, Dampness and Mould. Geneva: World Health Organization; 2009.

3. Kanchongkittiphon W, Mendell MJ, Gaffin JM, Wang G, Phipatanakul W. Indoor environmental exposures and exacerbation of asthma: an update to the 2000 review by the Institute of Medicine. Environ Health Perspect. 2015;123:6-20.

4. Mendell MJ, Mirer AG, Cheung K, Tong M, Douwes J. Respiratory and allergic health effects of dampness, mold, and dampness-related agents: a review of the epidemiologic evidence. Environ Health Perspect. 2011;119:748-756.

5. von Mutius E, Vercelli D. Farm living: effects on childhood asthma and allergy. Nat Rev Immunol. 2010;10:861-868.

6. Heederik D, von Mutius E. Does diversity of environmental microbial exposure matter for the occurrence of allergy and asthma? J Allergy Clin Immunol. 2012;130:44-50.

7. Braun-Fahrlander C, Riedler J, Herz U, et al. Environmental exposure to endotoxin and its relation to asthma in school-age children. $N$ Engl J Med. 2002;347:869-877.

8. Sordillo JE, Hoffman EB, Celedon JC, Litonjua AA, Milton DK, Gold DR. Multiple microbial exposures in the home may protect against asthma or allergy in childhood. Clin Exp Allergy. 2010;40:902-910.

9. Ege MJ, Mayer M, Normand AC, et al. Exposure to environmental microorganisms and childhood asthma. N Engl J Med. 2011;364:701-709.

10. Dannemiller KC, Reeves D, Bibby K, Yamamoto N, Peccia J. Fungal highthroughput taxonomic identification tool for use with next-generation sequencing (FHiTINGS). J Basic Microbiol. 2014;54:315-321.

11. Karvonen AM, Hyvarinen A, Rintala $\mathrm{H}$, et al. Quantity and diversity of environmental microbial exposure and development of asthma: a birth cohort study. Allergy. 2014;69:1092-1101.

12. Valkonen M, Wouters IM, Taubel M, et al. Bacterial exposures and associations with atopy and asthma in children. PLOS ONE. 2015;10:e0131594.

13. The European Community Respiratory Health Survey II Steering Committee. The European Community Respiratory Health Survey II. Eur Respir J. 2002;20:1071-1079.

14. Zock JP, Jarvis D, Luczynska C, Sunyer J, Burney P; European Community Respiratory Health Survey. Housing characteristics, reported mold exposure, and asthma in the European Community Respiratory Health Survey. J Allergy Clin Immunol. 2002;110:285-292.

15. Norback D, Zock JP, Plana E, et al. Mould and dampness in dwelling places, and onset of asthma: the population-based cohort ECRHS. Occup Environ Med. 2013;70:325-331.

16. Bornehag CG, Blomquist G, Gyntelberg F, et al. Dampness in buildings and health. Nordic interdisciplinary review of the scientific evidence on associations between exposure to "dampness" in buildings and health effects (NORDDAMP). Indoor Air. 2001;11:72-86. 
17. Burney P, Luczynska C, Chinn S, Jarvis D. The European Community Respiratory Health Survey. Eur Respir J. 1994;7:954-960.

18. Sunyer J, Pekkanen J, Garcia-Esteban R, et al. Asthma score: predictive ability and risk factors. Allergy. 2007;62:142-148.

19. Chinn S, Jarvis D, Burney P; European Community Respiratory Health Survey. Relation of bronchial responsiveness to body mass index in the ECRHS. Thorax. 2002;57:1028-1033.

20. Nowak D, Heinrich J, Jorres R, et al. Prevalence of respiratory symptoms, bronchial hyperresponsiveness and atopy among adults: west and east Germany. Eur Respir J. 1996;9:2541-2552.

21. Chinn S, Burney P, Jarvis D, Luczynska C. Variation in bronchial responsiveness in the European Community Respiratory Health Survey (ECRHS). Eur Respir J. 1997;10:2495-2501.

22. Zock JP, Heinrich J, Jarvis D, et al. Distribution and determinants of house dust mite allergens in Europe: the European Community Respiratory Health Survey II. J Allergy Clin Immunol. 2006;118:682-690.

23. Karkkainen PM, Valkonen M, Hyvarinen A, Nevalainen A, Rintala H. Determination of bacterial load in house dust using qPCR, chemical markers and culture. J Environ Monit. 2010;12:759-768.

24. Rintala H, Nevalainen A. Quantitative measurement of streptomycetes using real-time PCR. J Environ Monit. 2006;8:745-749.

25. Haugland R, Vesper SJ, Inventors; U.S. Environmental Protection Agency, Assignee. Method of identifying and quantifying specific fungi and bacteria. US patent 6387652. 2003.

26. Torvinen E, Torkko P, Rintala AN. Real-time PCR detection of environmental mycobacteria in house dust. J Microbiol Methods. 2010;82:78-84.

27. Haugland RA, Varma M, Wymer LJ, Vesper SJ. Quantitative PCR analysis of selected Aspergillus, Penicillium and Paecilomyces species. Syst Appl Microbiol. 2004;27:198-210.

28. Kaarakainen P, Rintala $H$, Vepsalainen A, Hyvarinen A, Nevalainen A, Meklin T. Microbial content of house dust samples determined with qPCR. Sci Total Environ. 2009;407:4673-4680.

29. Sebastian A, Larsson L. Characterization of the microbial community in indoor environments: a chemical-analytical approach. Appl Environ Microbiol. 2003;69:3103-3109.

30. Sebastian A, Harley W, Fox A, Larsson L. Evaluation of the methyl ester O-methyl acetate derivative of muramic acid for the determination of peptidoglycan in environmental samples by ion-trap GCMS-MS. J Environ Monit. 2004;4:300-304.

31. Saraf A, Larsson L, Burge H, Milton D. Quantification of ergosterol and 3-hydroxy fatty acids in settled house dust by gas chromatographymass spectrometry: comparison with fungal culture and determination of endotoxin by a Limulus amebocyte lysate assay. Appl Environ Microbiol. 1997;63:2554-2559.

32. Heine $\mathrm{H}$, Lien $\mathrm{E}$. Toll-like receptors and their function in innate and adaptive immunity. Int Arch Allergy Immunol. 2003;130:180-192.

33. Heumann D, Barras C, Severin A, Glauser MP, Tomasz A. Grampositive cell walls stimulate synthesis of tumor necrosis factor alpha and interleukin-6 by human monocytes. Infect Immun. 1994;62:2715-2721.

34. Saraf A, Larsson L, Larsson BM, Larsson K, Palmberg L. House dust induces IL-6 and IL-8 response in A549 epithelial cells. Indoor Air. 1999;9:219-225.

35. Weidemann B, Brade H, Rietschel ET, et al. Soluble peptidoglycaninduced monokine production can be blocked by anti-CD14 monoclonal antibodies and by lipid A partial structures. Infect Immun. 1994;62:4709-4715.

36. Lappalainen MH, Hyvarinen A, Hirvonen MR, et al. High indoor microbial levels are associated with reduced Th1 cytokine secretion capacity in infancy. Int Arch Allergy Immunol. 2012;159:194-203.
37. van Strien RT, Engel R, Holst O, et al. Microbial exposure of rural school children, as assessed by levels of $\mathrm{N}$-acetyl-muramic acid in mattress dust, and its association with respiratory health. J Allergy Clin Immunol. 2004;113:860-867.

38. Weber J, Illi S, Nowak D, et al. Asthma and the hygiene hypothesis. Does cleanliness matter? Am J Respir Crit Care Med. 2015;191:522-529.

39. Tischer $\mathrm{C}$, Zock JP, Valkonen $\mathrm{M}$, et al. Predictors of microbial agents in dust and respiratory health in the Ecrhs. BMC Pulm Med. 2015;15:48.

40. Taubel M, Rintala H, Pitkaranta M, et al. The occupant as a source of house dust bacteria. J Allergy Clin Immunol. 2009;124:834-840.e47.

41. Sordillo JE, Alwis UK, Hoffman E, Gold DR, Milton DK. Home characteristics as predictors of bacterial and fungal microbial biomarkers in house dust. Environ Health Perspect. 2011;119:189-195.

42. Pakarinen J, Hyvarinen A, Salkinoja-Salonen M, et al. Predominance of Gram-positive bacteria in house dust in the low-allergy risk Russian Karelia. Environ Microbiol. 2008;10:3317-3325.

43. Vartiainen E, Petays T, Haahtela T, Jousilahti P, Pekkanen J. Allergic diseases, skin prick test responses, and IgE levels in North Karelia, Finland, and the Republic of Karelia, Russia. J Allergy Clin Immunol. 2002;109:643-648.

44. Chen C, Thiering E, Doekes G, et al. Geographical variation and the determinants of domestic endotoxin levels in mattress dust in Europe. Indoor Air. 2012;22:24-32.

45. Gunnbjornsdottir MI, Norback D, Bjornsson E, et al. Indoor environment in three North European cities in relationship to atopy and respiratory symptoms. Clin Respir J. 2009;3:85-94.

46. Sharpe RA, Bearman N, Thornton CR, Husk K, Osborne NJ. Indoor fungal diversity and asthma: a meta-analysis and systematic review of risk factors. J Allergy Clin Immunol. 2015;135:110-122.

47. Reponen T, Lockey J, Bernstein DI, et al. Infant origins of childhood asthma associated with specific molds. J Allergy Clin Immunol. 2012;130:639-644.e5.

48. Vesper SJ, McKinstry C, Yang C, et al. Specific molds associated with asthma in water-damaged homes. J Occup Environ Med. 2006;48:852-858

49. WHO Regional Office for Europe. WHO Guidelines for Indoor Air Quality: Dampness and Mould. Copenhagen: WHO Regional Office for Europe; 2009

50. Norback D, Zock JP, Plana E, et al. Lung function decline in relation to mould and dampness in the home: the longitudinal European Community Respiratory Health Survey ECRHS II. Thorax. 2011:66:396-401.

51. Tischer CG, Heinrich J. Exposure assessment of residential mould, fungi and microbial components in relation to children's health: achievements and challenges. Int J Hyg Environ Health. 2013;216:109-114

\section{SUPPORTING INFORMATION}

Additional Supporting Information may be found online in the supporting information tab for this article.

How to cite this article: Valkonen M, Täubel M, Pekkanen J, et al. Microbial characteristics in homes of asthmatic and non-asthmatic adults in the ECRHS cohort. Indoor Air. 2018;28:16-27. https://doi.org/10.1111/ina.12427 